TITLE:

\title{
A NEW SPECIES OF RHOPALAEA FROM THE PACIFIC COAST OF COSTA RICA (TUNICATA, ASCIDIACEA)
}

$\operatorname{AUTHOR}(\mathrm{S}):$

Tokioka, Takasi

\section{CITATION:}

Tokioka, Takasi. A NEW SPECIES OF RHOPALAEA FROM THE PACIFIC COAST OF COSTA RICA (TUNICATA, ASCIDIACEA). PUBLICATIONS OF THE SETO MARINE BIOLOGICAL LABORATORY 1971, 19(2-3): 119-122

ISSUE DATE:

1971-10-30

URL:

http://hdl.handle.net/2433/175663

RIGHT: 


\title{
A NEW SPECIES OF RHOPALAEA FROM THE PACIFIC COAST OF COSTA RICA (TUNICATA, ASCIDIACEA) ${ }^{1)}$
}

\author{
TAKASI TOKIOKA
}

Seto Marine Biological Laboratory

With 1 Text-figure

Four specimens of a solitary ascidian collected in February - March, 1970 from Playas del Coco on the Pacific coast of Costa Rica by Drs. Birkeland and Spight were submitted to me for identification. They were fixed and preserved in formalin, and brilliant purple in colour when they reached me in April of the same year. Measurements of these specimens are:

$\begin{array}{ccccc}\text { Sp.No. } & \begin{array}{c}\text { Length of } \\ \text { body proper }\end{array} & \begin{array}{c}\text { Length of } \\ \text { attachment process }\end{array} & \text { Width } & \begin{array}{c}\text { Lateral } \\ \text { thickness }\end{array} \\ 1 & 20 \mathrm{~mm} & 13 \mathrm{~mm} & 12 \mathrm{~mm} & 6 \mathrm{~mm} \\ 2 & 25 & 12 & 17 & 6 \\ 3 & 35 & \text { not defined } & 17 & 8 \\ 4 & 44 & \text { not defined } & 18 & 10 .\end{array}$

As seen in the table given above, two larger specimens are seemingly attached to the substratum by the posterior end of the body, without forming any attachment extension clearly defined. Then, it is quite natural that the collectors sorted provisionally these specimens as a form of the Ascidiidae.

Dissecting the specimens, however, it was revealed that they were belonging to a form of Rhopalaea, but with the abdomen unusually small. Of course, this is because of the strong contraction of the abdominal musculature which must be highly developed. No matter how strong the contraction is, the original abdomen can never be of a significant length, as the proximal portion of the test body, which usually holds the abdomen and is hard and non-contractile, is practically not defined. For this unique feature of having the unusually small abdomen, it is proposed here to establish a new species for these specimens.

1) Contributions from the Seto Marine Biological Laboratory, No. 551.

Publ. Seto Mar. Biol. Lab., XIX (2/3), 119-122, 1971. (Article 10) 

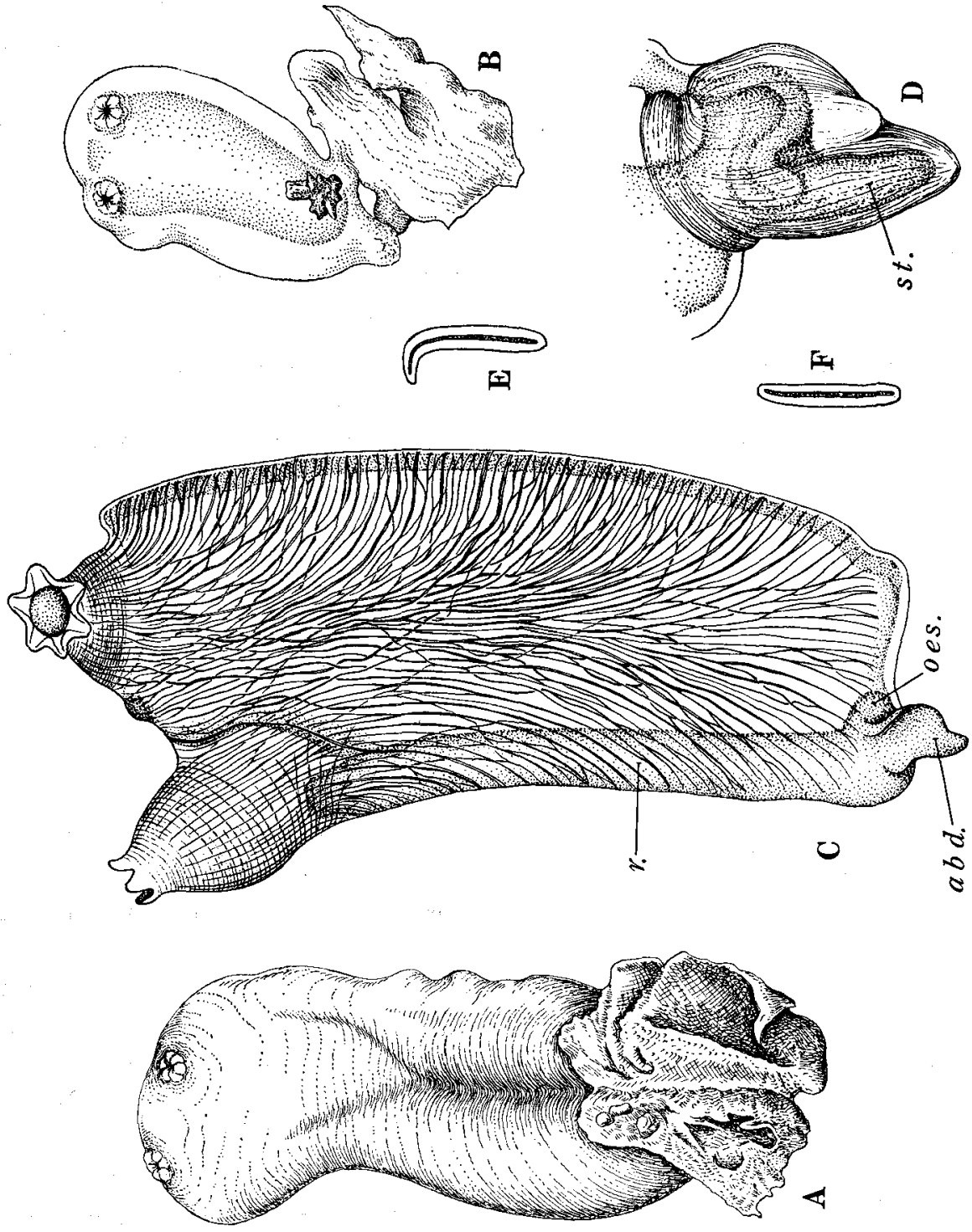

Fig. 1. Rhopalaea birkelandi n. sp. A-Sp. No. 4. B-Sp. No. 2. C-Mantle body of Sp. No. 4, right side. abd.: abdomen, oes.: oesophageal opening to branchial sac, $r_{.}:$rectum. DAbdomen of Sp. No. 4. st.: ?stomach. E, F-Ciliated grooves of Sp. No. 1 (F) and Sp. No. 4 (E). 


\section{Rhopalaea birkelandi $\mathrm{n}$. sp.}

The body is more or less elongate, spatulate, considerably compressed laterally, and attached to the substratum by the posterior end (fig. $1 \mathrm{~A}$ ) or by the attachment process formed at the posterior end of the body (fig. 1 B). Both apertures are sessile, at the distal edge of the body (fig. 1 A, in Sp. Nos. 1, 3 and 4) or on the right side very near the anterior edge (fig. $1 \mathrm{~B}$, in Sp. No. 2). The test is hard gelatinous or cartilaginous; $1-3 \mathrm{~mm}$ in thickness, thicker near the site of attachment and the anterior part of the body around the apertures; the surface is smooth and free from any incrusting materials. In a fresh state in April 1970, the test was brilliant purple in colour, but on June 11, 1971 when the specimens were dissected it was faded to pale purplish, though a little darker at the apertures; translucent, at least the outline of the ascending rectum being seen through.

The mantle body is represented mostly by the large thorax, the abdomen is extremely small and just like an appendant protuberance (fig. $1 \mathrm{C}$ ); $26 \mathrm{~mm}$ long thorax $+5 \mathrm{~mm}$ long abdomen for the $35 \mathrm{~mm}$ long individual (Sp. No. 3) and 30 $\mathrm{mm}$ long thorax $+2 \mathrm{~mm}$ long abdomen for the $44 \mathrm{~mm}$ long individual (Sp. No. 4). Both apertures 6-lobed and opened respectively on short, rather stout siphons; a small yellowish ocellus at each interval between lobes. The arrangement of thoracic muscles accords fundamentally with the general musculature type of the genus, namely the musculature consists roughly of dorsal and ventral groups of oblique to longitudinal muscles. In the present new species, however, there are much more numerous muscles on the thorax; the ventral half consists roughly of transverse to oblique muscles, while the dorsal half of oblique to longitudinal muscles; muscles of the ventral half and some ventral ones of the dorsal half converge to the branchial siphon. Sphincters of the apertures are laid beneath the longitudinal muscles. The anus is located very anteriorly, approximately at the anterior three-fourths; the margin is cut into several lobes, each further into a few lobules. The oesophageal opening to the branchial sac is located at the postero-dorsal corner of the sac.

Branchial tentacles 12, 6 larger and 6 smaller ones alternate regularly; rarely bifid ones may occur. The ciliated groove is a longitudinal slit (fig. $1 \mathrm{E}, \mathrm{F}$ ), situated at just the anterior end of the dorsal ganglion. No plications are formed on the wall of the branchial sac. Numbers of vessels are as follows:

$\begin{array}{lcccc}\text { Sp. No. } & \begin{array}{c}\text { Length of } \\ \text { specimen }\end{array} & \begin{array}{c}\text { Inner longitudinal } \\ \text { vessels }\end{array} & \begin{array}{c}\text { Transverse } \\ \text { vessels }\end{array} & \begin{array}{c}\text { Dorsal } \\ \text { languets }\end{array} \\ 1 & \begin{array}{c}20 \mathrm{~mm} \\ \text { (body proper) }\end{array} & 31 \text { (right side) } & 65 & 36 \\ 4 & 44 & 39 \text { (right side) } & 110 & 53 .\end{array}$

A few dorsal ones of the inner longitudinal vessels are imperfect. Supporting processes of the inner longitudinal vessel are bent dorsally, no projections beyond the 
vessel are issued from them. No parastigmatic vessels, about 4 stigmata in a mesh.

The abdomen is extremely short, in a strongly contracted state it is only 2 to 5 $\mathrm{mm}$ long for $26-30 \mathrm{~mm}$ long thorax; pinkish to dark purplish in colour. The stomach is seemingly situated near the posterior end of the abdomen. The details of the alimentary organs and gonads are uncleared because of a strongly contracted state of the abdomen, but only the rectum ascending along the branchial sac.

The new species is characterized by its unusually small abdomen. In this respect, it may be drawing near the state of the family Cionidae. The new species is named after Dr. Charles Birkeland, one of the collectors. Sp. No. 4 is kept as the holotype; and $\mathrm{Sp}$. Nos. 1-3 as paratypes.

At closing the description, I want to express my hearty thanks to Drs. Birkeland and SPIGHT for the chance of studying this interesting material. 